Chapter 8

\title{
Wood-Reinforced Polymer Composites
}

\author{
Anil Akdogan and Ali Serdar Vanli \\ Additional information is available at the end of the chapter
}

http://dx.doi.org/10.5772/66336

\begin{abstract}
The importance of protection of natural resources, recycling and biodegrability are the basic reasons behind the increased use of lignocellulosic (LC) material-reinforced polymer composites. This chapter investigates wood filler-reinforced polymer composites, which have gained attention among the researchers and in the market in woody applications having aesthetic and low service costs. Most polymers have the increasing cost of petrochemical products while LC materials are obtained from different national resources such as different types of wood powder. LC materials are available in light, cheap, environment-friendly forms with easy maintenance. The main disadvantages of LC-reinforced composites are moisture sensitivity and poor dimensional stability, besides changing wood fiber characteristics in time and poor adhesion to basically all kind of matrix polymers. Additive usage in manufacturing is an increasing trend of wood-based LC material-reinforced polymer composite parts to penetrate new markets, with better performance requirements and long-term stability. This chapter investigates description, classification, production with common additive types and usage of wood-polymer composite materials. In addition, it approaches preprocesses to reach high productivity and high-quality product manufacturing. Finally, some experimental manufacturing results of wood-reinforced polymer composites are presented.
\end{abstract}

Keywords: polymer composites, wood reinforcements, lignocellulosic materials, manufacturing methods, product quality

\section{Introduction}

Using lignocellulosic (LC) materials as filler has valued attention in the polymer composite production industry. While LC materials are obtained from different national resources like different types of wood powder, polymers have the increasing cost of petrochemical 
products [1]. The trend was provided both by exchanging petrochemical materials for increased bioderived sustainable materials and the need to reduce waste to landfill and explore recycling technologies. Wood polymer composite (WPC) products having wastepaper and/or second hand plastics into are some of the major components of global municipal solid waste which can be recycled [2,3]. Engineers and scientists have been working to improve the various qualifications of both thermosets and thermoplastics through the addition of wood fiber since the beginning of the twentieth century. The concept is still open to improve and seems will be for a long time. Fine powder of wood or woody biomass from agricultural residues is mixed with polymers such as polyethylene or polypropylene generally within an adjusted extruder. The extruded material can be pelletized for final processing of products by injection molding, extrusion or compression molding, or the extruded material may be formed into simple sections such as planks or more complex profiles for specific applications. LC filler might be obtained from different national resources such as nut shells and residual wood powder. The well-known form of wood filler for thermoplastics is wood powder. Wood powder can be defined as a finely granulated form of wood. It is derived from various wood shavings, sawdust, chips and other waste wood from saw mills and residues of other wood processing industries. Wood powder is available commercially in a variety of size distributions and species in the market [4].

LC materials are available in light, cheap, environment friendly forms with easy maintenance. Having lower cost per unit volume of wood fillers, low wear effects on processing machines and equipment, lack of health hazards, lower densities, abilities for surface modifications and their abundance in nature make them suitable solution in both filler and fiber forms compared to other inorganic fillers. The well-known handicaps of LC-reinforced composites are their moisture sensitivity and poor dimensional stability, besides changing wood fiber characteristics in time with origin and the time of the harvest and poor adhesion to basically all kind of matrix polymers. The main application areas of LC polymer composites are building, automotive, furniture and packaging industries besides flooring, fencing, trim board, windows, plywood, roofing and siding. Other applications are in infrastructure, e.g., boardwalks, marinas and guardrails; in transportation, e.g., interior automotive panels and dashboards, truck floors and head liners; and in industrial and consumer applications, e.g., playground equipment and pallets. Additionally, outdoor tables chairs, crossovers, sun shades and benches are already being made of wood polymer composites. The WPC can be used in food packaging industry as an alternative biodegradable product in the case of high percentage LC filler reinforcement [5-8]. The range of fibers and fillers are typically introduced at loadings, i.e., weight percentage, of $30-70 \%$ in the polymer, although laboratory studies reporting levels from $5 \%$ upward exist. Although the situation in tensile properties is more variable, continued improvement could be achieved in bending properties at high filler loadings [2]. Plastic as matrix and wood powder as filler constitute the main ingredients in WPC receipts. The weight percentage of wood powder varies in the receipts and wood powder content of up to $70 \%$ is currently used in commercial WPC products [4].

Products from WPCs have been manufacturing in industry for a long time. In practice, using polymer processing machines to produce WPC bring some important processing problems 
causing high production costs [5]. In order to overcome the hydrophilic nature of wood which is a big handicap and to improve the adhesion and compatibility of polymers to the cellulose of wood, researchers use preprocessing for recent years [7-9]. Much research has been centered on aspects of compatibility between the commonly used plastic matrix and the wood fiber or powder to accelerate WPCs performance [5, 6, 9-11]. Other efforts have been made to reduce the density, by foaming of the manufactured profile or by designing hollow sectioned parts for specific applications [2, 12]. WPCs are in general decrease material costs and increase stiffness, basically provided by lignin, compared to the virgin polymers at the expense of ductility and impact strength. In addition, these composites could be manufactured by existing cost-effective processing equipment with a few but important adjustments. It is therefore important to review the literature on wood filler material-reinforced polymer composites. In the literature, there are many works on production and characterization of various kinds of LC fillers and polymers prescribing valuable composite receipts [6, 7, 13-15].

Some researchers processed composites with wood powder and wood chips as filler and various PP grades as the matrix polymer. The measurement range for filler particle lengths and widths are in a wide range. Tensile strength, elongation at break and impact strength were significantly increased in composites reinforced with wood fibers, upon introduction of coupling agents. Scanning Electron Microscope (SEM) examinations revealed well-dispersed wood powders in the extruded compounds and injection molded test samples. The dispersion of the wood fiber quality was in general significantly improved by introduction of coupling agents [16]. In other work, researchers focused on extrusion and injection molding of different biocomposites, containing up to $70 \mathrm{wt} \%$ wood powder. In general, at higher filling levels, lower impacts of fiber content on mechanical properties were determined. The tensile and flexural strengths of all biopolymers were significantly improved except the poly-lactic acid. About $180 \%$ increase in tensile strength was achieved with the aliphatic-aromatic co-polyester produced from fossil resources at maximum fiber load of $65 \mathrm{wt}$ \% [ [6]. In another research work, using wood particle filler for WPC production suggest that processing of composites having wood content above $60 \%$ is highly challenging, especially where the wood particles are fine [14]. However, some researchers measured the length and diameter of the cellulose fibers to study how the different processing steps are affected by the dimensions of the fibers and their reinforcing capacity.

Additionally, the authors of this chapter made different investigations on the effects of three different dimensioned beech powder as additives to the morphological and mechanical properties of the polymer composite materials. At lower particle sizes of certain concentrations of wood powder loads result in better mechanical properties and morphological improvements of composites are experienced with a sharp decrease in the elongation at break. The scanning electron microscope (SEM) analysis (Figure 1) at fractured surfaces of tensile bars indicate that smaller filler sizes cause homogenize structures but if the fiber size is too small, the matrix cannot grip the fiber [5].

Moreover, there are some works considering wood fiber quality, fiber modification and especially thermal treatments on the physical and mechanical properties of WPCs. Tensile mechanical investigations show an increase in rigidity of the composites upon increasing wood 
powder content, together with a sharp decrease in the elongation at break. There were often slightly better results with the samples which had undergone a drying pretreatment $[6,9-11$, $13,14,16]$. Low resin ratio and viscosity, easy providing, low grain hardness and strength and also low cellular moisture features are desired for LC materials in order to use them in WPC products. Because of their available properties, it is possible to meet many of the herbal materials such as beech, pinewood, spruce, walnut, ailanthus, naturally desiccated grass pedicles and various kinds of plants, as composite material fillers in the literature [15, 17-20]. The basic reason of the growing usage of such natural fibers is their strong fiber structure. Producers are also penetrated into trim board and plywood markets using lightness, abrasiveness and environmental friendly specifications of the WPC materials [21, 22].

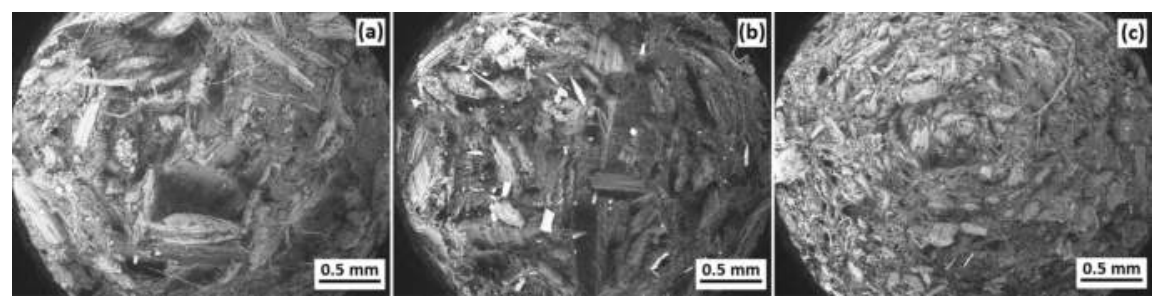

Figure 1. SEM micrographs of the fracture surfaces of the different size wood filler-reinforced composites (a) 1200$1800 \mu \mathrm{m}$ sieve mesh sized wood filler-reinforced composite (b) $800-400 \mu \mathrm{m}$ sieve mesh sized wood filler-reinforced composite (c) under of $400 \mu \mathrm{m}$ sieve mesh sized wood filler-reinforced composite [5].

\section{WPC compositions, types and preprocesses}

WPCs are made up of a matrix polymer and wood material as fiber or a few kinds of filler forms and various kinds of processing agents or additives. This chapter gives a brief review of WPC compositions, types and preprocessing applications.

Most synthetic polymers are derived largely from petrochemicals. Others are derived from natural resins such as gutta-percha, tar, rosins and other modified natural sources such as cellulose/hemicelluloses and protein. Polymer materials having covalent bonds provide rigid and strong bonding of atoms within long-chain molecules. Polyethylene (PE) is accepted as the simplest polymer. Molecular weight of a polymer can be determined by multiplying the molecular weight of the mer by the degree of polymerization. The properties of polymers are formed by the degree of polymerization. Generally, low degrees of polymerization are achieved for surface finishes even coatings; whereas, high degrees of polymerization are necessary for the polymers shaped by extrusion or injection molding. Thermoplastic polymers have no cross-linking, so that they can be reshaped by heating to evaluated temperatures; whereas, thermosetting polymers having extensive cross-linking are rigid and cannot be reshaped when heated. It means the extension of cross-linking between the long-chain molecules is a method of distinguishing the commercially available polymers [22]. Although thermoset polymers have higher thermal stability and lower water absorption compared to 
thermoplastics, the increased demand for recyclability aims the researchers and users at thermoplastic-based composites. Most of the single polymer plastics made of petroleum are relatively easy to recycle $[1,23]$. Commonly used manufacturing thermoplastic composites include polyethylene (PE) both high density (HD) and low density (LD) types, polypropylene $(\mathrm{PP})$, polyvinyl chloride (PVC), polyvinyledene fluoride (PVdF), polybutylene terephthalate (PBT), polyvinyledene oxide (PPO), acrylonitrile-butadiene-styrene (ABS), acrylonitrilestyrene-acrylate (ASA), polycarbonate (PC) and some others [24, 25]. On the basis of $\mathrm{T}_{\mathrm{m}}$ (melting temperature), the main three candidates are PE, PP and PVC. Their melting points are below $180^{\circ} \mathrm{C}$ and given in Table 1 with some other important specifications like $\mathrm{T}_{\mathrm{g}}$ (glass transition temperature) and densities. PE, PP, PVC including polystyrene (PS) are used in WPCs frequently because of their lower processing temperatures $\left(150-220^{\circ} \mathrm{C}\right)$ than the others which prevent the degradation of the reinforcement materials [4].

\begin{tabular}{llll}
\hline Polymer & $\mathrm{T}_{\mathrm{m}}\left({ }^{\circ} \mathrm{C}\right)$ & $\mathrm{T}_{\mathrm{g}}\left({ }^{\circ} \mathrm{C}\right)$ & Density $\left(\mathrm{g} / \mathrm{cm}^{3}\right)$ \\
\hline PE (LD) & $98-115$ & -125 & $0.91-0.92$ \\
PE (HD) & $120-137$ & -130 to 100 & $0.94-0.96$ \\
PP & $160-173$ & -20 to 0 & $0.90-0.91$ \\
PVC & $100-260$ & 80 to 87 & $1.16-1.38$ \\
\hline
\end{tabular}

Table 1. Three basic polymers with specifications.

The primarily limiting factor of the use of thermoplastics in WPC production is the thermal degradation of wood fiber. Typically, wood starts to degrade around $220^{\circ} \mathrm{C}$ and this serves as the upper limit for the melting point of thermoplastic matrix resins. Filler content in WPC is generally in the range of $40-70 \%$ by weight. Flexural modulus, heat distortion temperature and impact strength are the basic mechanical properties besides important physical expectations like densities considered by the investigators and users [1].

The chemical composition of wood filler is quite complex. It varies according to the species. It is determined in LC material classification. It is made up of cellulose/hemicellulose, lignin and many other extractives. Firstly, the main structural component of wood is cellulose. The cellulose molecule is almost totally linear. Cellulose functions as the primary structural and the most abundant component within the wood fiber cell walls. Cellulose is hygroscopic and water absorption of it depends on the number of free hydroxyl groups. Since hemicellulose has a short chain with a degree of polymerization, it has low molecular weight. Cellulose serves as connecting agent that links bonds to the micro fibrils providing a kind of structural reinforcement to the wood fiber cell wall. The typical L/D (fiber length to diameter ratio) of wood powder ranges from about 3 to 5 . Wood particles are generally defined by sieve mesh sizes. Secondly, lignin provides stiffness to wood by acting as cement in bonding the cellulose filaments. It is a brittle, an amorphous polymeric material, relatively inert that acts as both a bonding agent and a stiffening agent. Lignin can be thought of as a matrix that connects cellulose fibers to each other. They can be removed by some organic solvents or water. Finally, wood extractives are known as low molecular weight oleophilic compounds. Since they are 
organic substances, they can be removed by the related solvents. Extractives can include organic waxes, oils, fats, gums, carbohydrates, acids and resins at different percentages. Their common effects are hygroscopicity, permeability, long-term stability and durability of wood. Ether, alcohol or water extractions are the typical well-known extractives removed by the steam distillation $[1-2,4]$.

Preprocessing of the filler ranges from simple sizing/sieving to pulping and chemical modification of the surface, depending on the required quality specifications from the final application. Sizing of wood generally operates automatically at the designed shaking sieving machines. Since wood particles are generally defined by sieve mesh sizes, machines can include various screens. A typical sieving process can be supplied by an electric motor as automatically and consistently to feed the WPC mass production lines. As an example, three different sizes of mesh screens are placed to the designed shaking sieving machine to use in the experiments. The schematic drawing of the machine is given in Figure 2 [26].

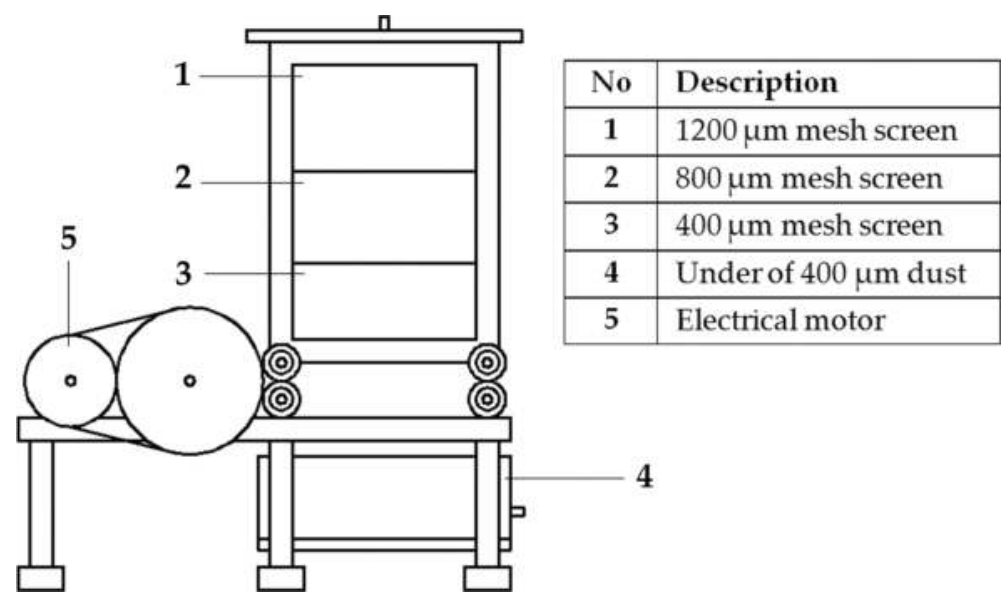

Figure 2. Shaking sieving machine [26].

Since interfacial adhesion between the polymer matrix and the wood filler defines the final physical properties of a WPC, in most WPC production operations, it is absolutely necessary to compatibilize or couple the mix. Various wood modification techniques used on solid wood to achieve dimensional stabilization besides polymer modification were investigated to assess the effect on bonding. In addition to the compatibilizers, techniques are frequently investigated which will alter the fiber surface chemistry or physical properties as a result of simple pretreatments [2]. In the literature for the modification of the wood fiber, much chemistry have been reacted with wood such as aldehydes, epoxides, anhydrides, siloxanes and isocyanates in an effort to compatabilize of wood for different polymer matrixes. It is clearly seen that as an alternative to the conventional pulping processes, solvent pulping method plays an important role [7, 10, 20,27]. Subsequently, many investigators have reported studies on the reaction of wood with a large number of alcohols. For instance, in a research work, switchgrass 
was used in the pulping trials. A laboratory digester, which was equipped with a liquor recirculation system and external indirect electric heating element, was used in the cooking process. After cooking, the material was de-fiberized in a blender and washed on a filter paper. The washed material was dried. The soda pulp from switchgrass supplied excellent mechanical properties and showed great potential as a reinforcement component [27]. On the other hand, wood chips were delignificated in glycerol solvent. At the end of delignification, wood washed with cold water and then with hot water until a clean filtrate was obtained. Due to its highly polar polyalcohol structure, glycerol could easily penetrate into the wood tissue. Thus, glycerol provides an effective reaction medium for delignification of wood chips. In addition, it was an excellent solvent for $\mathrm{Na}_{2} \mathrm{CO}_{3}$ and $\mathrm{NaOH}$ used as catalysts [28]. There are many other works pulping many kinds of LC materials or polymers at many different combinations of solvents $[7,15,20,29]$.

It is find out in the early researches that the interfacial bonding between the fiber and polyolefin matrix was very low. LC materials also would have high density of hydroxyl groups on their surface due to cellulose and hemicelluloses. Moreover, the lignin contains some polar functional groups. On the other hand, PE is a linear alkane of very high molecular weight, containing only repeating $\mathrm{CH}_{2}$ units. The surface-free energy of $\mathrm{PE}$ is $31 \mathrm{~mJ} / \mathrm{m}^{2}$; whereas, 32 $\mathrm{mJ} / \mathrm{m}^{2}$ for PP [30] and although the surface energy of wood is much higher, $40-60 \mathrm{~mJ} / \mathrm{m}^{2}$, it typically contributes only as $31.5 \mathrm{~mJ} / \mathrm{m}^{2}$ to the surface energy of WPCs [31]. This difference in surface energy can lead to poor dispersion of the fiber within the matrix in blending. It even results in relatively weak interfacial bonding between the two phases of the WPC. A wide range of compounds were investigated to overcome these difficulties in many researches [2].

The need for coupling agents to improve the fiber-matrix adhesion in LC material-filled composites is well-documented. Various methods to improve interfacial adhesion have been examined. Enhanced interfacial adhesion and aid in fiber dispersion can be supplied by coupling agents. A notified increase in interfacial adhesion between the polymer and the fiber certainly results an improvement in mechanical and rheological properties of the composite aiding processing ability $[1,5]$. Coupling agents become more critical growing product lifetime and strength requirements. Coupling agents used in WPCs play a vital role in adhesion between nonpolar polymeric matrix and polar wood fibers improving compatibility even in high filler loadings. Besides, increased filler loadings make the composites stiffer but reduce the toughness. Today, coupling agents are being used mostly in automotive and construction applications to improve long-term product performances. They help fiber dispersion, which results in reduced water absorption and better maintenance of mechanical properties after water exposure. Coupling agents increase flexural and tensile strengths and room temperature creep resistance. Moreover, heat deflection temperature increase by corresponding better creep resistance at elevated temperatures [32]. In general, wood filler improves the heat deflection of unfilled polymer matrix. Coupling agents can also aid in foaming by improving blend strength at the die exit and by conducting dispersion [33].

In the case of using polyolefins in WPC production, maleic anhydride-grafted polymers are widely being used in industry. Maleic anhydride grafted polypropylene (MAPE) and maleic anhydride grafted polyethylene (MAPP) appear like quite suitable agents, which are added to 
the blend. Small quantities of the MAPE or MAPP supply improvements in mechanical properties of the blend when added to the wood powder and polymer mix during compounding [8,34-37]. There are a large number of brands and grades of MAPP are available and it is nowadays one of the most commonly used compatibilizer in the PP used WPC industry; whereas, MAPE is widely accepted for the PE-based WPCs. The other popular coupling agents are presently being used include anhydrides, isocyanates, silanes and other anhydridemodified copolymers in industry. More than forty coupling agents are being used not only in research works but also in manufacturing for a long time. These agents are grouped as organics and inorganics. Organic agents are preferred much more than inorganic agents due to their stronger interfacial adhesion. Coupling agents are generally coated on the surface of wood filler, polymer or both by compounding, blending, mixing, soaking, spraying, or other methods [12]. These agents are used for wood fiber and other fillers to improve reinforcing ability over the functionality of the fiber surfaces. Also, the weight fraction of the ingredients affects the final physical properties of the blend. Such as block copolymers and surfactants are commercially available compatibilization chemistries. But the common commercially available coupling agents include derivatives of maleic anhydride or siloxanes as reactive groups.

Processing additive usage in manufacturing is an increasing trend of wood-based LC materialreinforced polymer composite parts to penetrate new markets with better performance requirements and long-term stability. The use of colorants and lubricants as additives is well established besides the others like antimicrobials to maintain both appearance and physical integrity and ultraviolet stabilizers which protect the polymer portion of the composite from degradation. Antimicrobial additives may be used, especially for outside usage such as decking, sliding and living set products. The customer may be concerned colorants against microbial attacks. It may also be necessary to protect the biodegradable woody component of the WPC material from microbial attacks as a result of high humidity conditions. Zinc borate is known as the most popular antimicrobial additive. Lubricants are typically used for increasing output volume of many extrusion processes [32]. Processing additives are generally added for better blending and improving the smoothness of the WPC product while profile getting out of the die. This can avoid forming alligator-type skin textures which are the results of high shear forces. Lubricants reduce shear between the filler and the polymer matrix and aid fine blending of the WPC. Moreover, fatty acid esters and alcohols or metal soap-like zinc stearate may be used for lubrication. While metallic stearate lubricants can interfere with the maleic anhydride functionalized polyolefin-coupling agents used in some WPCs, alternative lubricant systems are available [38].

On the other hand, foaming of extruded or injection molded parts takes great attention. Foaming of WPCs is achieved by dispersing a gaseous phase throughout the liquid polymer and filler to create foam comprising a polymer and included gas component. The preservation of the resultant foamed state is important to maintaining the required structural properties. Foamed WPC parts can be manufactured using either chemical, generating a foaming gas by a chemical reaction or physical, achieving foaming with any chemical change, blowing agents. Among them, foaming of WPC is getting increasingly important day by day. The primary benefits of foaming are lightening weight of the compound, improving durability of the 
product and decreasing costs of the manufacturing. Moreover, foaming increases stiffness and makes the WPC more like wood for cutting and assembling type operations [32]. Foaming helps to improve performances of wood-working tools and fasteners by reducing part density and improving stiffness. It reduces cycling times that increases process performance and productivity. Reduced weight makes WPC aid to use in both current and new applications. Since amorphous polymers, e.g., polyvinyl chloride and polystyrene have high melt strength, they can be foamed well. Crystalline polymers such as PP and linear PE are more difficult to foam because they have low melt strength and typically contain calcium stearate, which acts as a de-foamer. That is why choosing a compatible lubricant is also crucial. Foaming agent performance is dependent on the ability to blend, pressure practice and temperature control [37]. Considering all components, the prepared flow chart in Figure 3 would be helpful to summarize WPC to part manufacturing.

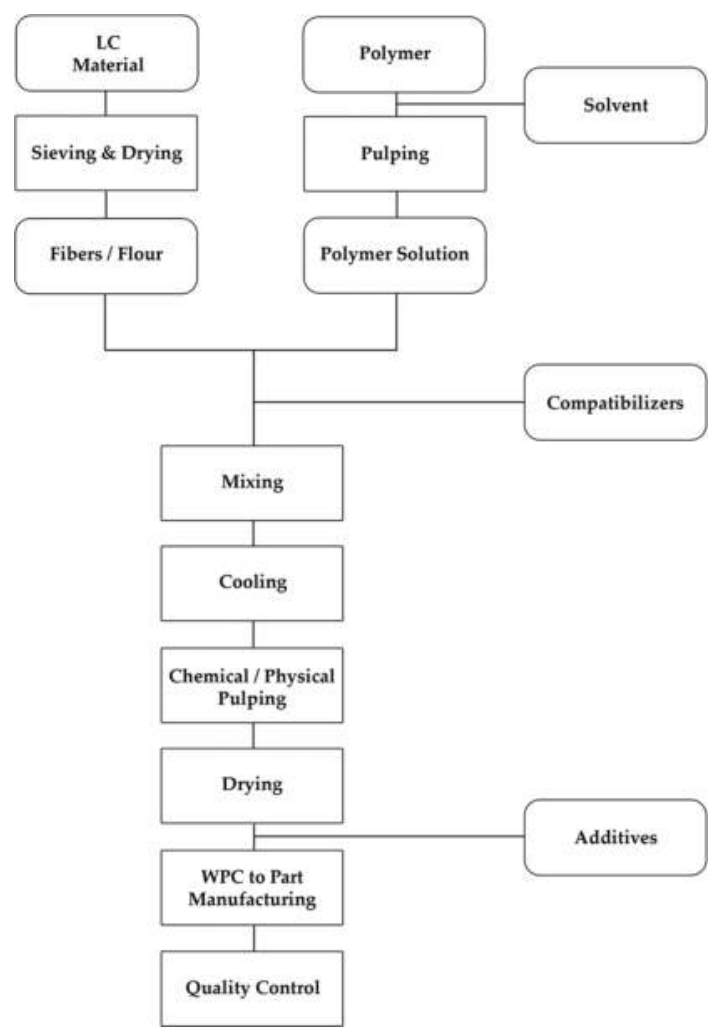

Figure 3. WPC to part manufacturing flow chart.

In addition, water absorption in finished parts is a basic problem for foamed WPC [32]. Control of moisture in the WPC production process is crucial because water anhydrides catalyze the polymer. The WPC material requires effective mixing, degassing and accurate metering 
processes and controlling the temperature. Of course, wood powder is very sensitive to moisture; it needs to be controlled. Moisture level of wood powder above $1 \%$ in the extruder causes production of micro-voids of irregular and inhomogeneous shapes which affect the usage performance of the products $[39,40]$. Wood contains moisture which amount must be reduced in acceptable levels for WPC production. Over moisture in LC materials affects the composite production process negatively. Considering this truth, wood scrap should be dried efficiently and homogeneously in a short time. Also the moistening of additive materials in storage conditions should be determined so that available time period of manufacturing for dehumidified material must be stated. Every manufacturer should determine this period according to their individual manufacturing parameters, the used LC material properties and the storage conditions.

The moisture affinity of the filler materials are investigated in the experiments [5]. The wood scrap used in the experiments was dried in the designed fluidized bed drying machine by the authors. The machine has three essential stations for the wood material. The first station, the back funnel, is a small part acting as a silo for the material. It is shown in Figure 4, with the number 6 . There is a decaying pitch screwed conveyor system under the back funnel. This system transfers the wood to the next station. Its rotational speed can be changed according to the desired raw material volume. The second station, the fluidized bed, is the main part of the machine acting as a pneumatic conveyor for the material. This station is shown with the number 8 . The fan, indicated by the number 11, rises up the solid particles in the fluidized bed. Fluid air temperature could be increased by a heat-controlled resistance placed inside or outside of the fluidized bed so that the required dry air can be achieved. However, inside temperature of the fluidized bed must be lower than the decomposition temperature of wood material. Otherwise, undesired burnings and ash formations may occur. Excess air can be evacuated by the filter cloth, shown by the number 5 , on the transmission channel. Then, the material is transferred to the pre-funnel indicated by the number 4 . After that, the material reaches the last station of the system, the heating bed, shown with the number 3 . The material is transferred into a glass flow channel by a stable pitch helical shaft, in which an infrared

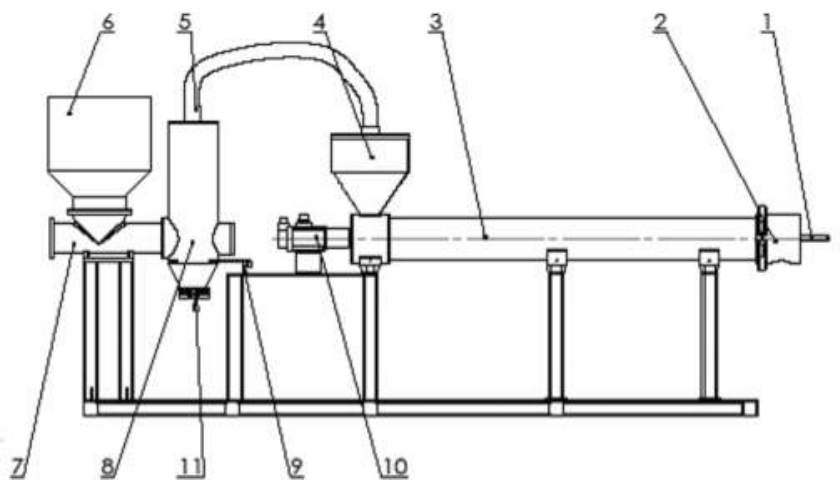

\begin{tabular}{|c|l|}
\hline No & Description \\
\hline $\mathbf{1}$ & Infrared Heater \\
\hline $\mathbf{2}$ & Evacuation Flange \\
\hline 3 & Heating Bed \\
\hline $\mathbf{4}$ & Pre-Funnel \\
\hline $\mathbf{5}$ & Filter Cloth \\
\hline $\mathbf{6}$ & Back Funnel \\
\hline $\mathbf{7}$ & Volumetric Dosing \\
\hline $\mathbf{8}$ & Fluidized Bed \\
\hline $\mathbf{9}$ & Single Track Valve \\
\hline $\mathbf{1 0}$ & Motor \\
\hline $\mathbf{1 1}$ & Fan \\
\hline
\end{tabular}

Figure 4. Schematic illustration of fluidized bed drying machine [26]. 
heater is fixed. Infrared heater temperature could be set digitally between 15 and $200^{\circ} \mathrm{C}$. Nitrogen could be injected into the glass flow channel for the purpose of deporting excess moisture and foreign particles. The flow channel has connection with an evacuation flange produced from polyamide at the end of the glass tube. Dried solid particles are shipped from the evacuation funnel. While infrared heat set at $85^{\circ} \mathrm{C}$, between 800 and $400 \mu \mathrm{m}$ sieve mesh sized $500 \mathrm{~g}$ powder has charged to the back funnel of the designed fluidized bed drying machine. At the end of $5 \mathrm{~min}$, the evacuated powder is weighted and the moisture loss is calculated. At the end of the five repeated tests $9.8 \mathrm{wt} . \%$ moisture loss for beech powder and $5.3 \mathrm{wt} . \%$ moisture loss for pine wood powder in average are calculated [26].

In this work, $100 \mathrm{~g}$ dried wood powder is left $36 \mathrm{~h}$ at the room conditions $\left(30 \% \mathrm{RH}, 23^{\circ} \mathrm{C}\right)$ and moisturizing behavior is determined. At the end of the time period, beech wood powder moistened at $2.27 \mathrm{wt} . \%$ [5]. Graphical representation of the beech wood and pine wood powder weight rise by moistening against the time is given in Figure 5. Pine wood sawdust weight rise is determined as $1.25 \mathrm{wt} . \%$.

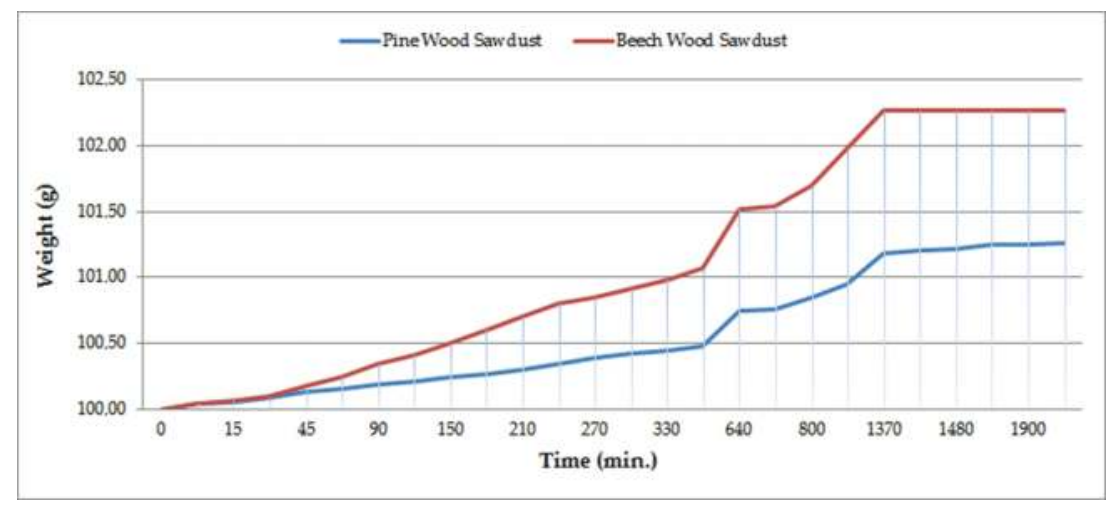

Figure 5. Beech wood sawdust and pine wood sawdust weight rises according to time.

\section{Manufacturing of WPC parts}

Product form, process performance attributes, costs and the easiest way of manufacturing are the basic factors for the selection of appropriate process technology of the WPCs. In manufacturing operations, it is a must to understand the interrelationship between the materials, the processing technique and the final product design like being in WPCs production. The primarily concerns of the selection of process technology include, but are not limited to, shaping the product, well-distributing the wood fiber within the matrix, encapsulating the wood fiber and high adhesion of wood filler to the matrix resin. This interrelationship has a direct effect on the quality of the composite. The majority of the WPC applications consider recycling as well. This basic requirement has primarily driven by the developed processing 
technologies for WPC production. Extrusion, injection molding and compression molding processing technologies represent these areas of development [1].

On the other hand, many investigators have reported studies on the reaction of wood with a large number of alcohols to supply high process performances, subsequently. When a simple chemical pretreatment is used to soften the wood, defibrated wood structure can be achieved easily. The wood particles with the highest aspect ratio (is the ratio of fiber length to diameter) are produced with pretreated and undried wood chips, which also had the highest flexural and impact strength properties [33]. It is proved in a research work that to achieve consistent feeding into the extruder which enabled manufacturing of highly filled cellulose fiber-PP composites could be possible by pelletizing of the cellulose fibers [13].

Among the production techniques, extrusion is the process by which heat and shear forces are applied to a polymer within the barrel of an extruding machine. Extruders are generally characterized by L/D ratio. In an extrusion process, several operations are carried out similar to compounding process. These are feeding, heating, conveying-mixing, melting, devolatization and pumping processes. Counter-rotating twin screw extruders are widely being used either in parallel or conical type. For solid profiles with less demanding application requirements, single screw extruders are more commonly being used. Although WPCs are in general compatible with existing cost-effective processing machines, in practice, using these machines to produce WPCs cause some important processing problems. In the cases of using high percentage LC filler materials, the WPC certainly will represent different rheological characteristics during the process. Since screw elemental process machines are required special screw designs and certain chemical lubricating and bonding additives, users need to re-design the extruders specifically as compounder type. So that, wood-based reinforcement percentage of the WPC composites could be increased. For instance, at first, LC material should be preprocessed instead of using it directly in WPC production to overcome many reported processing difficulties which cause low productivity and poor product quality.

The primary processing difficulties are high die-head pressures, low moisture content requirement of LC material, high energy consumption and low mechanical and thermal efficiencies. High production costs and low productivity would probably be experienced as a result of these main difficulties. In this context, researchers focus on the investigation of woodpolymer composites compounding and production performances effective on production abilities and productivity. Compounding refers to an intimate mixing including dispersive and then distributive units in addition to the standard extrusion operations.

Several different configurations of twin screw extruders are suitable for achieving the desired final attributes and in executing the sequence of unit operations. General machine configurations are single-screw extruders, conical or parallel counter-rotating twin-screw extruders and planetary type screw extruders. Such machines used in the plastic industry cannot be used in the LC material-reinforced polymer composite production unless they are specifically redesigned to meet the requirements of WPC materials processing requirements. If the screw elemental process machines are going to be used especially for WPC manufacturing, high speed mixing and certain chemical lubricating and bonding are required. Sections of the screw may be re-designed to enhance compounding or blending, using lugging tools rather than a 
continuous screw flight. Additional hoppers should be assembled to feed the wood filler and other additives such as colorant or lubricant masterbatchs, antimicrobials or fire retardants. Port areas or venting channels are needed to allow steam and volatile gases to exit the system. They are generally assembled to the extruders used in WPC production to avoid blows or defects in the extruded part during processing. There are many other aspects to consider in extruder selection, starting from screw geometry to operating parameters which influence the flow, level of mixing and many other product properties such as feed rate, screw speed and barrel temperature $[2,5,40]$.

It is an essential need to consider the quality of the products. In the extruder, the most important component is the screw, which is divided into three categories. The first is the feeder section where feeding takes place, the second is the transition section where melting happens and the third is the metering section where the product is pushed at a uniform rate and pressure through the die [22]. The extruder should be capable of consistently deliver the thermally homogeneous material to the die at high pressures. Die design is critical to ensure uniform melt delivery across the die to minimize cross-channel velocity gradients and resulting physical property gradient effects because of the complex content and high viscosity of the composites. Die design may be quite complex especially for hollow sectioned profiles of many kinds of geometries and various materials having different rheology and shrinkage behaviors. The nature of matrix resins affects total shrinkage behavior of the composite. Die entrance and exit angel designs are the key factors affecting the mechanical properties of the composites [1].

Injection molding process is similar to metal die casting in most respects. It is used to produce many kinds of products from toys to automobile parts. Injection molding is nearly for one third of polymeric material processing types as being a versatile process. The aim of conventional injection molding is the mass production of parts with complex geometries at low costs and high production rates. However, the range of materials is limited with thermoplastic or thermoset polymers. In the case of using natural fibers with high aspect ratios in automotive applications, reaction injection molding, structural reaction injection molding and reinforced reaction injection molding processes are very common. Modern injection molding machines use the reciprocating screw for plasticization, the same as for extrusion, but the screw is stopped and then being used as a plunger. Plunging injects the hot polymer into the mold cavity [22].

To sum up, most of the composites used in constructive applications are extruded to a profile of uniform solid or hollow cross section at any length, whereas products having more complex shapes such as being in the automotive industry or other consumer products are injection or compression molded [41]. Products such as decking, railings and window or door profiles readily exude themselves to extrusion through a two-dimensional die. Injection-molded applications such as consumer household goods and furniture parts are gaining importance due to the high consumption rates of these kinds of products. Thermoforming or compression molding method is especially preferable for automotive industry [4]. Besides, microcellular injection molding process is a novel method using supercritical gases mixed with polymer melt in the barrel and then a single-phase polymer gas solution is created. This process can find wide application areas in WPC production especially for the automotive industry. 


\section{An experimental work on WPC production}

Commercially available virgin low density polyethylene (LDPE) was used in the conducted experimental works. The basic properties of the LDPE are; $20 \mathrm{~g} / 10 \mathrm{~min}$. MFI at $190^{\circ} \mathrm{C} / 2.16 \mathrm{~kg}$, $0.923 \mathrm{~g} / \mathrm{cm}^{3}$ density and $10.5 \mathrm{MPa}$ tensile strength. The used additives were $1 \mathrm{wt} . \%$ slip and anti-blocking agent and $1 \mathrm{wt} . \%$ as coupling agent. Similarly, commercially available beech wood powder was provided from one of the lumber market. The filtered and sieved beech wood powder was operated in the pulping bath, consisting of $10 \% \mathrm{Na}_{2} \mathrm{SO}_{3}$ (wt.\%), for $30 \mathrm{~min}$ at $95^{\circ} \mathrm{C}[6,28]$. After grinding, the processed filler wood material is mixed with the virgin polymer. The compound ratio was $50 \mathrm{wt}$ \% of pulped wood reinforcement and $48 \mathrm{wt} \%$ LDPE.

After mechanical mixing, the mixture was transferred to the constructed compounding extruder. A compounder type extruder was designed for the production of WPC considering polymer feeding sections, heating and distributing parts with an adapted melt pump system for the compression. The extruder is a single-screw compounding machine. The barrel has a diameter of $30 \mathrm{~mm}$, a length of $800 \mathrm{~mm}$ and consists of 6 zones with separate temperature control units. The stable thermal conditions practiced for WPC production are listed in Table 2.

\begin{tabular}{lllllll}
\hline Heat zones & $\mathbf{1}$ & $\mathbf{2}$ & $\mathbf{3}$ & $\mathbf{4}$ & $\mathbf{5}$ & $\mathbf{6}$ \\
\hline $\mathbf{T}\left({ }^{\circ} \mathrm{C}\right)$ & 120 & 130 & 140 & 140 & 130 & 120 \\
\hline
\end{tabular}

Table 2. Thermal conditions practiced for WPC production.

As the processing parameters, the extruder screw speed was set to $110 \mathrm{rpm}$ at $20 \mathrm{~Hz}$ frequency and the machine torque was changed 0.37 to $0.57 \mathrm{Nm}$ during the processes. Schematic illustration of the designed compounding extruder is given in Figure 6.

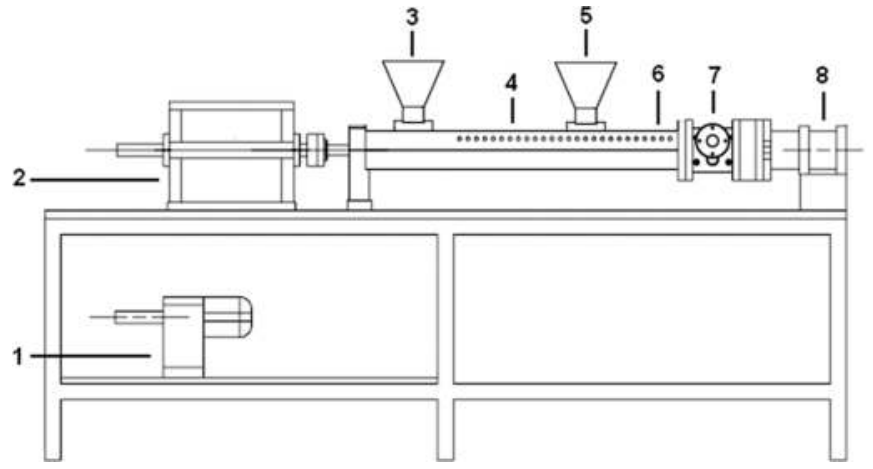

\begin{tabular}{|c|l|}
\hline No & Description \\
\hline $\mathbf{1}$ & Electrical Motor \\
\hline $\mathbf{2}$ & Reduction Gear \\
\hline $\mathbf{3}$ & First Feed Hopper \\
\hline $\mathbf{4}$ & Single Screw \\
\hline $\mathbf{5}$ & Second Feed Hopper \\
\hline $\mathbf{6}$ & Barrel \\
\hline $\mathbf{7}$ & Spin Pump \\
\hline $\mathbf{8}$ & Extrusion Die \\
\hline
\end{tabular}

Figure 6. Schematic illustration of the compounding extruder. 
The maximum operating temperature was $140^{\circ} \mathrm{C}$ at all trials. Although polyolefin is a viscose material, the transferred heat to the LC material affects the viscosity of the WPC in a negative way. The required low viscosity of the materials enables processing at low temperatures. So that, extruding requires low pressure and could enhance high productivity by the reduction in the cycle time. Due to the low temperature and low pressure requirements, energy consumption and thermal degradation of natural fillers can be reduced as well. As observed in the experiments, giving viscose friction energy to the LC material throughout the extrusion process is not only wasting the energy but also causing chemical deformation of the material. That is why researchers are oriented to modify manufacturing techniques for LC material filled polymer composite production instead of using conventional machines.

In this experimental work, pulped and dried wood powder is delivered from the first feed hopper of the compounding extruder to the fluidized bed by the screw to mix with polyolefin. After that, polyolefin and LC are mixed homogeneously by the screw at lower squeezing and higher mixing rates. Finally, the mix is pressurized by a gear pump to manufacture the final profile at the die. The die gravure is designed for circular bars. After cutting this raw material into small pieces, the final product is manufactured in a single screw extruder. The pictures of circular bars as raw WPC material and trim boards as final WPC products can be seen in Figure 7, respectively.

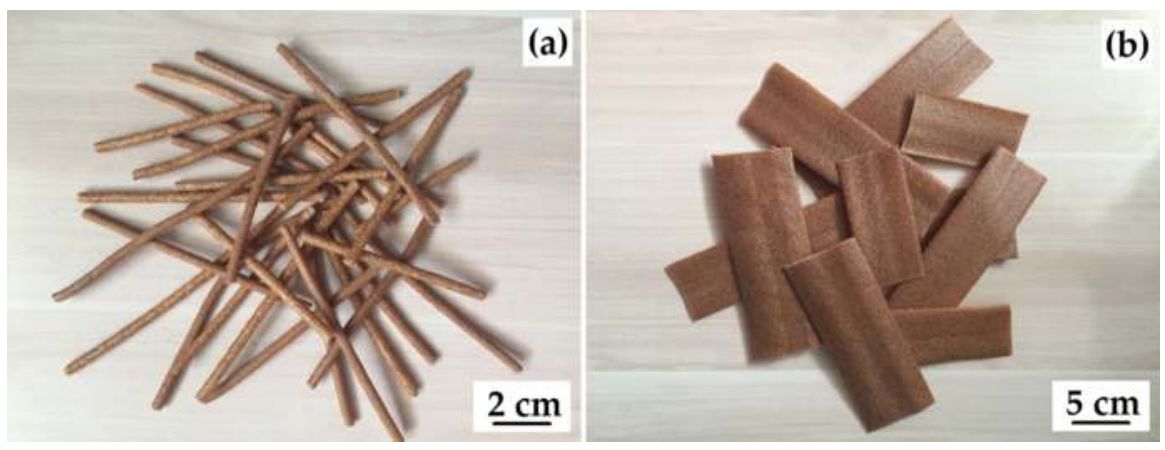

Figure 7. Pictures of (a) circular bars as raw WPC material and (b) trim boards as final WPC products.

In order to find out the mechanical properties of manufactured parts, tensile tests were conducted in accordance with the ISO 527-2 standard on a Schimadzu tensile tester, Japan, AG-X type with a load cell of $100 \mathrm{kN}$ and a universal extensometer [42]. The flexural tests were carried out according to the ISO 178 standard [43]. The repeated mechanical test results of the manufactured composites are given in Table 3. It is observed that mechanical qualifications of the produced wood-polymer composites have been enhanced regarding to the virgin PE. With the help of pelletization process and machine improvements, high productivity manufacturing was succeeded. 


\begin{tabular}{lllll}
\hline Tests & $\begin{array}{l}\text { Flexural } \\
\text { strength (MPa) }\end{array}$ & $\begin{array}{l}\text { Elongation at } \\
\text { flexural break (\%) }\end{array}$ & Tensile strength (MPa) & Elongation at tensile break (\%) \\
\hline 1st & 48.80 & 3.11 & 16.75 & 0.62 \\
2nd & 54.20 & 1.63 & 16.95 & 0.90 \\
3rd & 54.50 & 2.90 & 18.05 & 1.80 \\
4th & 43.10 & 2.21 & 18.25 & 1.85 \\
5th & 50.10 & 2.82 & 17.70 & 1.60 \\
Mean & $\mathbf{4 9 . 9 4}$ & $\mathbf{2 . 5 3}$ & $\mathbf{1 7 . 5 4}$ & $\mathbf{1 . 3 5}$ \\
\hline St. deviation & $\mathbf{4 . 6 5}$ & $\mathbf{0 . 6 1}$ & $\mathbf{0 . 6 6}$ & $\mathbf{0 . 5 6}$ \\
\hline
\end{tabular}

Table 3. Mechanical test results of the manufactured composites.

Since screw design is very important for WPC production, several simulations should be performed on screws according to the expected attitudes from them. In this experiment, the authors performed some simulations on the screw's longitudinal plane considering pressure and velocity flows by ANSYS CFD 13.0 software program. The simulation method is based on computational fluid dynamics (CFD) refers to the use of the numerical techniques to solve fluid dynamical problems. Numerical techniques consist of a very broad range of methods including, but not limited to, finite difference methods (FDM), finite element methods (FEM), finite volume methods (FVM) and boundary element methods (BEM). The pressure contours on a longitudinal plane is represented in Figure 8, showing the maximum at the end of the metering section as expected. The generated heat is transported by convection in the axial direction; while in the radial direction convective exchanges are limited, resulting in a complex temperature field which cannot properly be described using a single normal profile. The analysis of velocity field shows that a relative intensity mixing is present at the end of the screw, as shown in Figure 9. The flow velocity profile near the barrel wall is high, decreasing to zero at the screw root. The figures also indicate that the gradients for the velocity and the pressure show a typical polymer flow profile in the metering section.

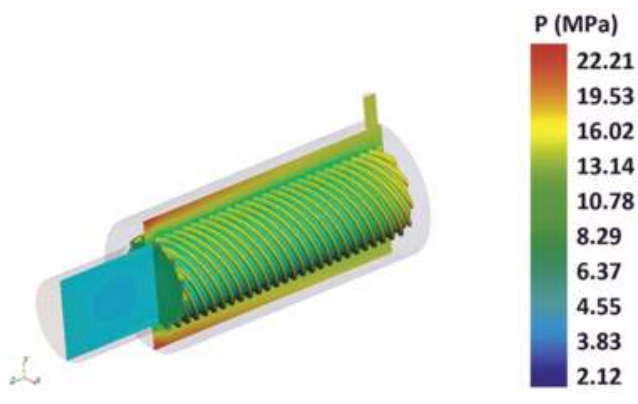

Figure 8. Pressure contours on a longitudinal plane. 

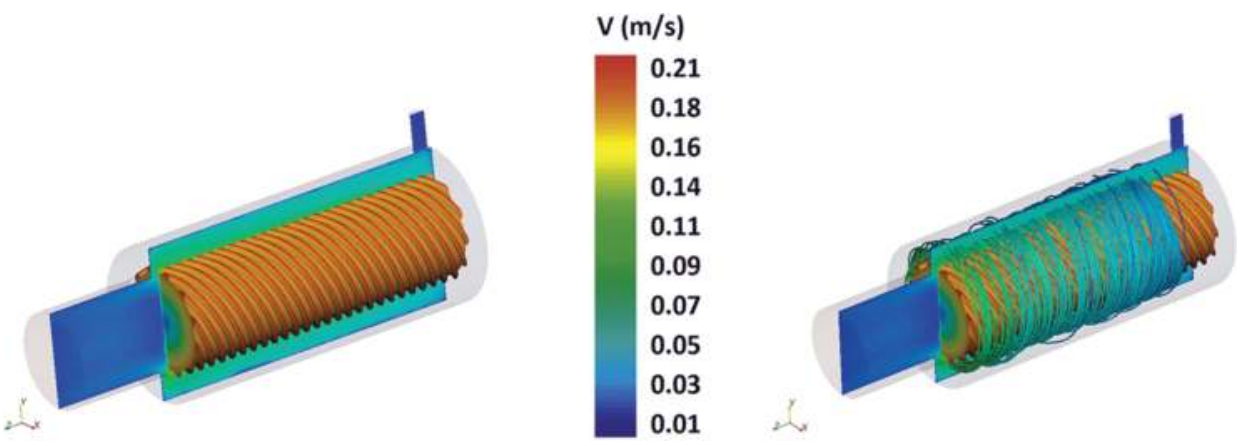

Figure 9. Velocity contours on a longitudinal plane.

\section{Conclusions and future works}

LC materials used in WPC productions can be derived from a variety of natural sources. Geographical resources are the drivers of filler material type and choice. It is clear that the use of LC fibers will continue to rise. However, the type of fiber in a geographic location is dictated by the factors including, but not limited to, availability, price, yield and required mechanical properties.

Wood powder is commercially processed from industrial waste materials such as planer shavings, chips and sawdust. During WPC production, the addition of wood powder into the plastic matrix significantly reduces the tensile and flexural strengths of the composite due to the poor interfacial adhesion between wood powder and the matrix in case not to using of coupling agents. The addition of coupling agents has many positive effects on the strength of WPC parts supplying an enhanced interfacial adhesion between wood powder and plastic matrix.

Nowadays, there are various methods to improve the most important usage performances of WPC parts. Besides stiffness, wood fiber reinforcement improves creep resistance, bending and tension abilities of WPC parts. WPC is less capable of necking than virgin polymer, so strain at break is lower and the Young's modulus is higher due to the stiffening effect of the wood particles; however, improvement in tensile strength is not guaranteed, whereas bending strength is generally higher. To increase the strength and modulus values of tensile and flexural tests, the use of compatibilizer is inevitable. The increasing usage of coupling agents would aid further cost decreases in WPCs. New LC sources include paper mill sludge and biorefinery residues. Because wood and LC fibers can lead to superior WPC properties by acting more as reinforcement than as filler, the present trend is to move toward the use of wood and other LC fibers in additional strength requirements.

All sources of variation in manufacturing operations are accepted as crucial. In order to optimize the complete manufacturing line and the process for WPC products, it is essential to 
operate each step of the manufacturing and all process parameters by well-characterized design of experiment techniques and methods. Subsequently, with the use of in wide variety optimization techniques, the best combinations of all operations can minimize downtime and costs while maximizing productivity and composite performance characteristics even considering the environment. Moreover, production technologies increasingly shift in favor of composites especially when life cycle costs are inevitably considered. Today, techniques are needed to develop for many applications. Improvements and changes in manufacturing methods will help to make preparation for the next generation WPCs. New processes under development are coextrusion and foaming during extrusion process. Inline coating technologies are one of the primary interests of the researchers nowadays.

Long life time resistance of the WPCs at many applications continues to be an issue of the researchers. Specifically, moisture uptake targeting is being considered in developing technologies. Commercially available chemicals or additives that absorb water, thereby limiting degradation of the WPC, are on the rise, especially for outdoor applications. Moreover, novel composites, nanocomposites, including the use of nanofibers derived from wood and other LC materials are taking great attention recently. Finally, concerning the environmental awareness of the users, researchers are working on completely green composite materials requiring the development of polymers that are totally biodegradable and environment friendly. WPCs are not only facing present requirements of consumers but also will high probably meet their further concerns by conducting developments in the field.

\section{Author details}

Anil Akdogan* and Ali Serdar Vanli

*Address all correspondence to: nomak@yildiz.edu.tr

Mechanical Engineering Department, Yildiz Technical University, İstanbul, Turkey

\section{References}

[1] Shankar G. Thermoplastic wood fiber composites. In: Mohanty A K, Misra M, Drzal L T, editors. Natural fibers, biopolymers and biocomposites. 1st ed. Boca Raton: CRC; 2005. pp. 348-386.

[2] Spear M J, Eder A, Carus M. Wood polymer composites. In: Ansell M P, editor. Wood composites. 1st ed. Cambridge: Woodhead; 2015. pp. 195-249. doi:10.1016/ B978-1-78242-454-3.09994-7

[3] Najafi S K. Use of recycled plastics in wood plastic composites-a review. Waste Management. 2013;33(9):1898-1905. doi:10.1016/j.wasman.2013.05.017 
[4] Matuana L M, Stark N M. The use of wood fibers as reinforcements in composites. In: Faruk O, Sain M, editors. Biofiber reinforcements in composite materials. 1st ed. Cambridge: Woodhead; 2015. pp. 648-688. doi:10.1533/9781782421276.5.648

[5] Akdogan A, Vanli A S. Material characterization of different-dimensioned wood particle-reinforced polymer composites. Journal of Thermoplastic Composite Materials. 2013;26(9):1237-1248. doi:10.1177/0892705713484743

[6] Sykacek E, Hrabalova M, Frech H, Mundigler N. Extrusion of five biopolymers reinforced with increasing wood flour concentration on a production machine, injection moulding and mechanical performance. Composites Part A: Applied Science and Manufacturing. 2009;40(8):1272-1282. doi:10.1016/j.compositesa.2009.05.023

[7] Sarul I T, Akdogan A, Koyun A. Alternative production methods for lignocellulosic composite materials. Journal of Thermoplastic Composite Materials. 2010;23(3):375384. doi:10.1177/0892705709345954

[8] Hietala M, Samuelsson E, Niinimaki J, Oksman K. The effect of pre-softened wood chips on wood fibre aspect ratio and mechanical properties of wood-polymer composites. Composites Part A: Applied Science and Manufacturing. 2011;42(12):2110-2116. doi: 10.1016/j.compositesa.2011.09.021

[9] Islam MS, Hamdan S, Hasan M, Ahmeda A S, Rahman M R. Effect of coupling reactions on the mechanical and biological properties of tropical wood polymer composites (WPC). International Biodeterioration \& Biodegradation, 2012;72:108-113. doi:10.1016/ j.ibiod.2012.05.019

[10] Bengtsson M, Baillif M L, Oksman K. Extrusion and Mechanical properties of highly filled cellulose fiber-PE composites. Composites Part A: Applied Science and Manufacturing. 2007;38:1922-1931. doi:10.1016/j.compositesa.2007.03.004

[11] Morreale M, Scaffaro R, Maio A, La Mantia F P. Effect of adding wood flour to the physical properties of a biodegradable polymer. Composites Part A: Applied Science and Manufacturing. 2008;39(3):503-513. doi:10.1016/j.compositesa.2007.12.002

[12] ReedyM.New chemicalfoamingagentsexpandwood/plasticcompositemarket.Plastics, Additives \& Compounding. 2002;4(5):24-26. doi:10.1016/S1464-391X(02)80114-3

[13] Felix J S, Domeno C, Nerin C. Characterization of wood plastic composites made from landfill-derived plastic and sawdust: volatile compounds and olfactometric analysis. Waste Management. 2013;33:645-655. doi:10.1016/j.wasman.2012.11.005

[14] Jam NJ, Behravesh A H. Flow behavior of HDPE-fine wood particles composites. Journal of Thermoplastic Composite Materials.2007;20:439-451.doi:10.1177/0892705707082324.

[15] Kücük M, Demirbas A. Kinetic study on hydrolysis of biomass (ailanthus altissima chips) by using alkaline-glycerol solution. Energy Conservation and Management. 1999;40(13):1397-1403. doi:10.1016/S0196-8904(99)00031-X 
[16] Nygard P, Tanem B S, Karlsen T, Brachet P, Leinsvang B. Extrusion-based wood fiberpp composites: wood powder and pelletized wood fibers-a comparative study. Composites Science and Technology. 2008;68(15-16):3418-3424. doi:10.1016/j.compscitech.2008.09.029

[17] Gosselin R, Rodrigue D, Riedl B. Injection molding of postconsumer wood-plastic composites I: morphology. Journal of Thermoplastic Composite Materials. 2006;19:639_ 657. doi:10.1177/0892705706067484

[18] Gosselin R, Rodrigue D, Riedl B. Injection molding of postconsumer wood-plastic composites II: mechnacial properties. Journal Of Thermoplastic Composite Materials. 2006;19:659-669. doi:10.1177/0892705706067486

[19] Schirp A, Mannheim M, Plinke B, Influence of refiner fibre quality and fibre modification treatments on properties of injection-moulded beech wood-plastic composites. Composites: Part A. 2014;61:245-257. doi:10.1016/j.compositesa.2014.03.003.

[20] Akhtar M, Scott G, Swaney R, Shipley D. Biomechanical pulping: a mill-scale evaluation. Resource, Conservation and Recycling. 2000:28:241-252. doi:10.1016/ S0921-3449(99)00048-8

[21] Danyadi L, Janecska T, Szabo Z, Nagy G, Moczo J, Pukanszky B. Wood flour filled PP composites: compatibilization and adhesion. Composites Science and Technology. 2007;67(13):2838-2846. doi:10.1016/j.compscitech.2007.01.024

[22] Bledzki A K, Letman M, Viksne A, Rence L. A comparison of compounding processes and wood type for wood fibre-PP composites. Composites Part A: Applied Science \& Manufacturing. 2005;36(6):789-797. doi:10.1016/j.compositesa.2004.10.029

[23] Colling D A, Vasilos T. Industrial materials, volume 2: polymers, ceramics and composites. 1st ed. Columbus: Pearson; 1995. p. 256.

[24] Seethamraju KV, Beaverson NJ, Heikkila KE. Advanced compatible polymer wood fiber composite. Andersen Corporation. US Patent Number 5981067-A; 9 November 1999.

[25] Carpenter M J, Sweetman G W. Tool for coldforming. Sandvik Intellectual Property Ab. US Patent Number 5948523-A; 7 September 1999.

[26] Vanli A S, Akdogan A, Koyun A. Fluidized bed drying system for continuous processing of lignocellulosic polymer composite materials. In: Proceedings of International Journal of Arts and Sciences Conference (IJAS ‘09); 9-13 November 2009; Gottenheim. New Britain: IJAS. 2009;3(1):43-49.

[27] Law K N, Kokta B V, Mao C B. Fibre morphology and soda - sulphite pulping of switchgrass.Bioresource Technology.2001;77(1):1-7.doi:10.1016/S0960-8524(00)00140-1

[28] Demirbas A. Aqueous glycerol delignification of wood chips and ground wood. Biosource Technology. 1998;63(2):179-185. doi:10.1016/S0960-8524(97)00063-1

[29] Baroulaki I, Karakasi O, Pappa G, Tarantili P A, Economides D, Magoulas K. Preparation and study of plastic compounds containing polyolefins and post used newspaper 
fibers. Composites Part A: Applied Science and Manufacturing 2006;37(10):1613-1625. doi:10.1016/j.compositesa.2005.10.012

[30] VanKrevelenDW, TeNijenhuisK.Properties of polymers: their correlation with chemical structure; their numerical estimation and prediction from additive group contributions. 4th ed. Amsterdam: Elsevier; 2009. p. 1032. doi:10.1016/B978-0-08-054819-7.00043-1

[31] Gupta B S, Reiniate I, Laborie M P G. Surface properties and adhesion of wood fiber reinforced thermoplastic composites. Colloids and Surfaces A: Physicochemical and Engineering Asppects. 2007;302(1-3):388-395. doi:10.1016/j.colsurfa.2007.03.002

[32] Markarian J. Additive development aid growth in wood plastic composites. Plastics, Addities \& Compounding. 2002;4(11):18-21. doi:10.1016/S1464-391X(02)80174-X

[33] MarkarianJ.Wood-plasticcomposites:currenttrendsinmaterialsandprocessing.Plastics, Additives \& Compounding. 2005;7(5):20-26. doi:10.1016/S1464-391X(05)70453-0

[34] Keener T J, Stuart R K, Brown T K. Maleated coupling agents for natural fiber composites. Composites Part A: Applied Science and Manufacturing. 2004;35(3):357-362. doi: 10.1016/j.compositesa.2003.09.014

[35] Nourbakhsh A, Karegarfard A, Ashori A, Nourbakhsh A. Effects of particle size and coupling agent concentration on mechanical properties of particulate-filled polymer composites. Journal of Thermoplastic Composite Materials. 2010;23(2):169-174. doi: $10.1177 / 0892705709340962$

[36] Leu S Y, Yang T H, Lo S F, Yang T H. Optimized material composition to improve the physical and mechanical properties of extruded wood-plastic composites (WPCs). Construction and Building Materials. 2012;29:120-127. doi:10.1016/j.conbuildmat. 2011.09.013

[37] Migneaulta S, Koubaab A, Perrec P, Riedl B. Effects of wood fiber surface chemistry on strength of wood-plastic composites. Applied Surface Science. 2015;343:11-18. doi: 10.1016/j.apsusc.2015.03.010

[38] Markarian J. Process modifiers improve output and cost competitiveness. Plastics, Additives \& Compounding. 2006;8(6):20-23. doi:10.1016/S1464-391X(06)70660-2

[39] Rizvi G, Matuana L M, Park C B. Foaming of PS/wood-fiber composites in extrusion using moisture as a blowing agent. Polymer Engineering \& Science. 2000;40(10):21242132. doi:10.1002/pen. 11345

[40] Matuana L M, Mengeloglu F. Manufacture of rigid PVC/wood-flour composite foams using moisture contained in wood as foaming agent. Journal of Vinyl \& Additive Technology. 2002;8(4):264-270. doi:10.1002/vnl.10373

[41] Yeh S K, Gupta R K. Improved wood-plastic composites through better processing. Composites Part A: Applied Science and Manufacturing. 2008;39(11):1694-1699. doi: 10.1016/j.compositesa.2008.07.013 
[42] ISO 527-2: 2012. Plastics - determination of tensile properties-part 2: test conditions for moulding and extrusion plastics, 2nd ed. International Standard Published; 2012; p. 11 .

[43] ISO 178: 2010. Plastics-determination of flexural properties, 5th ed. International Standard Published; 2011; p. 19. 